\title{
0 acolhimento como princípio da mediação da informação
}

Marcos Aparecido Rodrigues do Prado

Doutor em Ciência da Informação pela Universidade Estadual Paulista "Júlio de Mesquita Filho" (UNESP). Professor Adjunto no curso de Biblioteconomia da Universidade Federal de Alagoas (UFAL).

marcos.prado@ichca.ufal

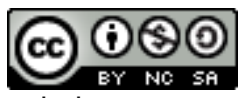

Este trabalho está licenciado com uma Licença Creative Commons - AtribuiçãoNãoComercial-Compartilhalgual 4.0

Internacional.

\section{Resumo}

Apresenta uma reflexão teórica que defende o acolhimento como um princípio fundamental no processo de mediação da informação. Trata-se de uma pesquisa estruturada na revisão de literatura que busca notabilizar a necessidade de percepções sociais visando ampliar o compromisso humanizador do bibliotecário. $\mathrm{Na}$ metodologia foi empregada a pesquisa bibliográfica em que a seleção de publicações continha o direcionamento temático sobre mediação da informação nos domínios da Biblioteconomia e Ciência da Informação. As definições conceituais de acolhimento foram extraídas de artigos científicos levantados em revistas especializadas de saúde pública disponíveis na fonte eletrônica SciELO. Este estudo tem como objetivo geral oferecer aportes teóricos que substanciam o embasamento nas atividades do fazer bibliotecário visando contemplar o usuário de bibliotecas e demais ambientes e equipamentos informacionais pela mediação da informação. Aborda o acolhimento considerando as diferenças e subjetividades individuais no usuário, enquanto sujeito histórico e social. $\mathrm{Na}$ conclusão oferece argumentações finais que remetem à necessidade do aprofundamento de estudos contínuos a fim de se priorizar o tratamento oferecido aos usuários pelas atividades de mediação da informação. Portanto, o presente artigo representa uma reflexão teórica visando expandir a potencialidade do compromisso social desempenhado pelo bibliotecário pela mediação da informação.

Palavras-chave: Mediação da Informação. Acolhimento. Usuário da informação.

\section{The Embracement as a Principle of Information Mediation}

\section{Abstract}

It presents a theoretical reflection that defends embracement as a fundamental principle in the process of mediation of information. It is a structured research in the literature review that seeks to highlight the need for social perceptions in order to expand the librarian's humanizing commitment. In the methodology, bibliographic research used the selection of publications contained the thematic direction on information mediation in the domains of Library Science and Information Science. The conceptual definitions of embracement extracted from scientific articles collected in specialized public health journals available in the electronic source SciELO. This study has the general objective of offering theoretical contributions that substantiate the foundation in the activities of librarianship aiming to contemplate the user of libraries and other environments and informational equipment through the mediation of information. It addresses the embracement considering the differences and individual subjectivities in the user, as a historical and social subject. In the conclusion, it offers final arguments that refer to the need for further studies in order to prioritize the treatment offered to users by information mediation activities. Therefore, this article represents a theoretical reflection aimed at expanding the potential of the social commitment performed by the librarian through the mediation of information.

Keywords: Information Mediation. User embracement. Information user. 


\section{Introdução}

A mediação da informação tem se consolidado no domínio da Biblioteconomia e da Ciência da Informação pelo crescimento frequente de publicações científicas a respeito do tema. Os estudos de Gomes (2010) confirmam claramente essa afirmativa. Assim, a mediação da informação assume pertinência indiscutível para oferecer contribuições teóricas significativas à atuação do bibliotecário, seja pelas atividades implícitas ou explícitas. Deste modo, Almeida Júnior (2015) reconhece que o Serviço de Referência e Informação (SRI) tem se beneficiado diretamente por embasamentos teóricos que antes havia lacunas. No entanto, a mediação da informação reflete a um processo complexo que requer o engajamento dos profissionais envolvidos a fim de se estabelecer princípios estruturantes na cultura organizacional da biblioteca.

Frente a estes desafios encontra-se a subjetividade do usuário com as suas peculiares necessidades de informação que são apresentadas para manifestar o interesse por recursos e serviços oferecidos pela biblioteca. Mas a mediação da informação deve ser orientada por princípios de acolhimento a esse usuário, considerando o respeito às diferenças como valor fundamental.

À primeira vista, constrói-se uma ideia de que o acolhimento se refere a um atributo natural e automaticamente conexo com o processo de mediação da informação. Mas esta forma espontânea e instintiva de se estabelecer paralelos nos tratamentos oferecidos pelas discussões teóricas predominantes de mediação da informação não representa uma realidade compatível com as expectativas preliminares. Sendo assim, considera-se necessário e oportuno proporcionar reflexões que direcionem entendimentos sobre a ideia de mediação da informação baseada em princípios do acolhimento ao usuário de biblioteca.

É importante destacar que algumas áreas de especialidades, como as ligadas à saúde pública, ao serviço social e à educação, oferecem inúmeras publicações sobre o tema de acolhimento, incluindo um farto aparato de discussões conceituais. Logo, o acolhimento aqui tratado encontra forte influência do amparo referencial apresentado pelas publicações de saúde pública, tomando como base a premissa de universalização do acesso. No entanto, vale esclarecer que há estrita convergência na aplicação teórica de publicações direcionadas à saúde pública com as preocupações relativas ao ambiente informacional das bibliotecas, considerando fundamentalmente as reflexões da mediação da informação.

Faz-se necessário destacar que o levantamento bibliográfico empreendido inicialmente encontrou poucos trabalhos que foram identificados com esta preocupação temática por busca realizada diretamente na Base de Dados em Ciência da Informação (BRAPCI). Ou seja, há escassas pesquisas em Biblioteconomia e Ciência da Informação que efetivamente dão importância para 0 acolhimento ao ponto de evidenciar essa temática por terminologias adotadas pelos respectivos campos de título, resumo e/ou palavras-chave.

Metodologicamente, o presente estudo foi estruturado em uma ampla revisão de literatura com embasamentos teóricos que se sustentam por argumentações caracterizadas por reflexões sobre o acolhimento. Assim, os aspectos fundamentais de mediação da informação foram levantados por pesquisa bibliográfica em publicações especializadas de Biblioteconomia e Ciência da Informação. Já as definições conceituais de acolhimento foram extraídas de artigos disponíveis em revistas científicas de saúde pública indexadas na fonte eletrônica SciELO.

Assim, o presente artigo representa um esforço para se ampliar a potencialidade do acolhimento como característica fundamental a ser explorada pela mediação da informação. Com isso, busca-se refletir o papel social das atividades bibliotecárias frente aos desafios necessários para enaltecer significativamente o usuário como prioridade no tratamento das relações de mediação da informação.

\section{Mediação da Informação e o Acolhimento ao Usuário}

A mediação da informação consiste em um processo altamente dinâmico, flexível e dotado de reformulações nas estratégias dos envolvidos para orientar e estruturar diretrizes visando alcançar os recursos pretendidos. Assim, se refere a um movimento frequentemente articulado por atitudes de escolhas premeditadas, reflexões ponderadas e decisões assertivas. Logo, "A ideia da mediação vai além do pensamento de conciliação e/ou acordo entre duas partes, está relacionada ao fazer, a uma ação, a uma intervenção" (SANTOS NETO; ALMEIDA JÚNIOR, 2017, p. 254). Com isso, a mediação não pode, de modo algum, ser entendida como esforços sucedidos para a entrega de um "pacote" de itens opcionais previamente selecionados pelo 
bibliotecário como resposta da demanda informacional. Todavia, no processo de mediação da informação não há o predomínio da inércia que imobilize a ação ou condicione a uma situação estagnada, pronta e acabada, ou seja, completamente estática no espaço e no tempo. A mediação da informação cursa um movimento diligente para situações dinâmicas e necessidades efêmeras, tudo isso acarretado pelo envolvimento das subjetividades tanto do usuário quanto dos profissionais.

É pela mediação da informação que o bibliotecário amplia as suas possibilidades de pensar e agir em função prioritária do seu usuário. É pela capacidade estruturante da mediação da informação que a organização institucional da biblioteca sistematiza políticas que acolhem o seu usuário considerando fundamentalmente os aspectos de incorporação das subjetividades diversas. Pois mediar exige uma interferência procedimental para atender as necessidades informacionais advindas de uma comunidade usuária familiarizada pelo novo e contemporâneo, especialmente por fatores de comunicações e relações sociais.

Para fins de elucidações didáticas, considera-se oportuno recorrer a uma definição conceitual que tradicionalmente as pesquisas sobre o tema na Ciência da Informação a utilizam com frequência. Deste modo, apoia-se em Almeida Júnior (2015, p. 25) para considerar que, conceitualmente, mediação da informação se entende como:

Toda ação de interferência - realizada em um processo, por um profissional da informação e na ambiência de equipamentos informacionais -, direta ou indireta; consciente ou inconscientemente; singular ou plural; individual ou coletiva; visando a apropriação de informação que satisfaça, parcialmente e de maneira momentânea, uma necessidade informacional, gerando conflitos e novas necessidades informacionais.

Pela definição apresentada se percebe a ênfase operacionalizada na interferência situacional visando alcançar o objetivo de satisfação do usuário sem que isso signifique uma tentativa de pacificar o seu interesse informacional. Muito pelo contrário, há indicativos de se provocar conflitos no usuário visando que este sujeito apresente novas demandas informacionais à biblioteca, enquanto centro e/ou sistema de informação. Portanto, há um caráter provocativo nesse processo em que "[...] a mediação não é passiva, ela é intencional, ainda que não seja de modo consciente" (SANTOS NETO; ALMEIDA JÚNIOR, 2017, p. 255).

É importante acrescentar que a ideia de satisfação informacional contida na definição conceitual utilizada sobre o processo de mediação da informação tem como base um princípio de aspiração do ideal e não como alcance efetivo. Pois, segundo Almeida Júnior (2015, p. 26), "Nenhuma necessidade informacional é totalmente clara nem será totalmente satisfeita". Para o autor mencionado há complexidades envolvidas que impedem a realização plena da expectativa à qual nem sempre o usuário consegue expressar com clareza a sua necessidade de informação. Afinal, são diversos os fatores de influência que levam um sujeito a procurar os serviços de informação oferecidos por bibliotecas. Muitos desses motivos que impulsionam alguém a requerer assistência profissional, a fim de se alcançar soluções informacionais, estão intimamente relacionados às questões pessoais do usuário. Deste modo, Almeida Júnior (2015, p. 27) considera que "Essas necessidades são geradas pelo pertencimento a um grupo, uma comunidade, uma tribo". Tais características enfatizam a premência pelo conhecimento antecedente dos usuários para se identificar a origem do problema que gerou a necessidade de informação. A combinação dos estudos de usuários e da comunidade com o desenvolvimento criterioso da entrevista de referência são fatores primordiais e indispensáveis para compor as estratégias na mediação da informação.

O intuito deliberado que sustenta o interesse hábil e arguto da mediação da informação é a apropriação da informação pelo usuário da biblioteca. "Sendo assim, tal apropriação deve ser entendida como um processo individual, concretizado na alteração, na modificação, na transformação do conhecimento do usuário" (ALMEIDA JÚNIOR; BORTOLIN, 2008, p. 76). Por conseguinte, é simplista ou, até mesmo, determinista, condicionar a noção de mediação da informação meramente com o atendimento ao usuário pela assistência prestada no Serviço de Referência e Informação. Muito provavelmente essa percepção distorcida se confunda com a ideia de mediação relacionada como atributo da disseminação. No entanto, Almeida Júnior (2008, p. 46) esclarece que "Ao contrário da disseminação, a mediação não estaria restrita apenas às atividades relacionadas diretamente ao público atendido, mas em todas as ações do profissional bibliotecário, em todo o fazer desse profissional". Neste sentido, se nota claramente o realce proposital do autor supracitado que caracteriza a mediação da informação como um processo amplo e estabelecido em todas as tarefas bibliotecárias e não vinculada a uma atividade específica e determinada. 
Obviamente que pensar a mediação da informação é atribuir a devida e merecida complexidade a ser assumida durante a rotina do fazer que está inerente nas competências do bibliotecário pelo exercício do seu protagonismo social. Pois esta condição "[...] representa o caminho humanizador do mundo e, portanto, promissor na construção ética de relações sociais capazes de assegurar espaço crítico, de dialogia, criatividade e alteridade" (GOMES, 2017, p. 28). Frente a esta postura estruturante de um modelo socializador da informação e arquétipo da percepção sobre as singularidades individuais nos espaços da biblioteca se encontram difusas as formas de acolhimento ao usuário.

Dentre as características delineadas para se estabelecer a dimensão estrutural do acolhimento para o usuário na biblioteca está o processo de interação verbal, contendo elementos significantes tanto na mediação explícita quanto nas suas formas implícitas. Vale destacar que, segundo Souto (2010, p. 66), "A interação verbal pode ocorrer não apenas presencialmente, utilizando-se da voz, mas também, utilizando-se de texto escrito". Ou seja, a interferência informacional é latente e repercute de diversas formas discursivas que imprimem determinados propósitos formalmente registrados ou não.

Em tais aspectos, são evidenciadas as relações de interatividades do usuário com os recursos informacionais oferecidos pelas bibliotecas, incluindo os parâmetros de tratamento linguísticos dispensados a estes. Assim, segundo Santaella (2011), a linguagem assume um protagonismo significativo no processo de mediação da informação em decorrência da representação comunicacional. Concordando com essa perspectiva, Silva (2009, p. 70) menciona que "A mediação manifesta-se na emergência de uma linguagem, de um sistema de representações comum a toda uma comunidade, a toda uma cultura". Consequentemente, o acolhimento pela mediação da informação se dá muito além das perspectivas de atendimento ao usuário pelo bibliotecário, em condições presenciais ou virtuais. Pois consiste em incrementar amplos repertórios que amparem representatividade e identificação visando estabelecer "[...] acesso ao mundo físico, afetivo, sensório, perceptivo, cognitivo, pela mediação dos signos" (SANTAELLA, 2011, p. 208). Logo, simbolicamente, a mediação da informação representa uma linguagem de tratamento visando acolher o usuário concebendo a biblioteca como um espaço de identificação e representatividade social. Em vista disso, Arruda e Oliveira (2017, p. 224) enfatizam que "A linguagem é, portanto, o eixo dos processos de mediação [...]". Diante de tais circunstâncias, a mediação da informação, especialmente nas suas formas implícitas, detém o poder de representação social pela seletividade da linguagem utilizada para estabelecer comunicação na biblioteca.

Varela (2007, p. 45) esclarece que as formas de "Representações são construções do mundo (inclusive do próprio homem) e das ações cujo objeto pode ser o conteúdo do mundo". Daí a importância da linguagem para se convencionar modelos sistematizados que favoreçam a amplitude política do acolhimento desejado para o usuário da biblioteca. Os efeitos dessa estratégia processual não se limitam nos tradicionais atendimentos ao usuário, especialmente pelo Serviço de Referência e Informação, mas também pelas atividades características da mediação implícita. Já que as intenções envolvidas estão carregadas de "[...] embates por poder, por dominação, por imposições de conceitos, verdades. O ideológico não é eliminado pelo emprego de técnicas documentais, ao contrário, estas reforçam esse caráter ideológico presente na construção da informação" (ALMEIDA JÚNIOR, 2015, p. 12).

E se a expressão humana comunicada pela linguagem detém componentes que figuram em esquemas de representação, logo o controle desta operação remete ao fascínio profissional e institucional sobre os comportamentos humanos, inclusive para recuperação e uso da informação. Pois, conforme advertem Almeida Júnior e Bortolin (2008, p. 74), "A linha que separa a interferência da manipulação é extremamente tênue". Apesar dos receios pela intervenção maniqueísta, ressalta-se que a mediação da informação é um processo rico do envolvimento profissional e deve ser tratado com muita seriedade por políticas institucionais para operacionalizar atitudes procedimentais. No entanto, é preciso separar os níveis de inclusão e exclusão que sobrepõem as interações estabelecidas socialmente pela mediação da informação em um determinado ambiente informacional, inclusive nas bibliotecas.

Mas, valendo-se de todos os esforços, é preciso manter consciência de que este processo não configura uma ação despretensiosa, isenta, imparcial ou neutra. Afinal, evolve a ideia de acesso à informação e este atributo configura o insumo do conhecimento, algo altamente cobiçado por remeter seduções pelo poder e controle. A informação possibilita o desenvolvimento de capacidades cognitivas para interpretar criticamente as realidades históricas, sociais e culturais. Nessa condição socialmente construída pelo empoderamento ocasionado por meio da informação, o preconceito e a discriminação podem ser evidenciados ou denunciados. Com isso, a importância da informação se dá pela sua capacidade de articulação da consciência coletiva e pela autonomia manifesta na liberdade do pensamento individual. Já que a informação é efêmera e 
condicionada ao tempo e ao espaço ela segue um processo dinâmico e construtivista em que "[...] vai se construindo, se impregnando de intenções, interesses, desejos, valores" (ALMEIDA JÚNIOR, 2015, p. 12). Daí a importância da biblioteca estruturada por princípios em que a mediação da informação prioriza o acolhimento de seus usuários.

\section{Acolhimento como Princípio Fundamental na Biblioteca}

Acolhimento pressupõe a disposição de ações voltadas para amparar e resguardar os diretos alheios visando estabelecer um relacionamento de respeito às diferenças individuais. Deste modo, acolher "[...] congrega a noção de humanidade plural, que ao negar a existência de um centro do saber, aceita a diversidade de culturas e é capaz de apreender os costumes alheios a partir da diferença (MITRE; ANDRADE; COTTA, 2012, p. 2076). Notadamente, trata-se de uma concepção da sensibilidade humana que identifica na empatia como característica fundamental para se combinar e se perceber as inúmeras formas de relações sociais. Lopes, Vilar, Melo e França (2015, p. 116) entendem que, "No seu sentido legítimo, o acolhimento pretende humanizar as relações [...]".

Envolvido por este compromisso de acolhimento ao usuário, o bibliotecário tem condições de possibilitar o desenvolvimento de múltiplas oportunidades para manifestar explicitamente os valores de empatia e respeito com as diversidades sociais. Com isto, são viabilizadas as condições propícias para se construir os elos afetivos desencadeados por meio de ações profissionais em que se impera o vínculo social pela recuperação e assimilação da informação. Assim, estima-se que o envolvimento profissional com o usuário gere uma relação recíproca e caracterizada por noções de familiaridade mútua em que o bibliotecário respeita as subjetividades do usuário e este igualmente entenda a importância social da mediação da informação.

Faz-se necessário realçar com esclarecimentos fundamentais que o acolhimento não deve ser visto como algo isolado de um processo ou uma simples atividade desarticulada de uma intenção propositiva. Logo, tomando como base Trindade (2010, p. 13), se compreende que: "O acolhimento não é um local, nem um espaço, mas uma postura ética, não exige hora ou profissional, implica saberes, escutar angústias, procurar solucioná-las tomando para si a responsabilidade de "abraçar" o usuário ou comunidade com resolubilidade".

Assim, é pela atitude de um profissionalismo engajado que o acolhimento representa um valor instituído para se manifestar efetivamente na participação interativa do bibliotecário com intuito de oferecer a devida assistência ao usuário. E, tomando como um processo sistematizado, o acolhimento se caracteriza como um "[...] modelo de ajuda, que requer dos profissionais habilidades pessoais para se interessar, compreender e responsabilizar-se pelos problemas do usuário" (MITRE; ANDRADE; COTTA, 2012, p. 2076).

Mas, destaca-se que a ideia de acolhimento envolve diretamente as deduções implicadas no conhecimento prévio das necessidades informacionais dos usuários reais e potenciais, sujeitos constituintes da comunidade atendida pela biblioteca. Neste sentido, torna-se crucial a realização de estudos de usuários e comunidade. Pois, "Assim, o acolhimento tende a lidar com pessoas conhecidas com problemas conhecidos, ainda que complexos" (TESSER; POLI NETO; CAMPOS, 2010, p. 3621). Deste modo, a ênfase do acolhimento se dá pela prioridade de percepção e identificação das necessidades captadas e levantadas sobre as particularidades e subjetividades características de grupos e pessoas.

Pensando a biblioteca como espaço público de socialização da diversidade humana, o acolhimento deveria constituir um princípio fundamental. Mas, para isso, é necessário que haja intervenções administrativas voltadas ao desenvolvimento de uma cultura organizacional comprometida e moldada por valores éticos. Ou seja, "[...] a reorganização dos serviços a partir da problematização dos processos de trabalho, além de mudanças estruturais na forma de gestão para ampliar os espaços democráticos de discussão, de escuta e de decisões coletivas" (MITRE; ANDRADE; COTTA, 2012, p. 2073).

Apesar da ênfase nas questões de gerenciamento institucional da biblioteca como fator agregador de compromissos com o acolhimento ao usuário, este processo não exime o papel dos cursos de graduação em Biblioteconomia. Pois, segundo Ferraz (2014, p. 25), é necessário que haja "[...] a formação de novos profissionais, aptos a lidarem com esta atividade tão desafiadora, mas ao mesmo tempo tão prazerosa e recompensadora". 
Para estabelecer o acolhimento como princípio instituído no âmbito organizacional da biblioteca é preciso enfrentar os desafios que retardam e impedem as mudanças necessárias. Neste sentido, deve-se considerar como etapa preliminar o entendimento gerencial de que "O acolhimento modifica radicalmente o processo de trabalho" (FRANCO; BUENO; MERHY, 1999, p. 348). Portanto, contemplar o acolhimento como forma expressa para caracterizar um princípio fundamental, instituído em políticas de ações no atendimento ao usuário, requer fazer alterações substanciais na cultura organizacional. Pois essa atitude deve se basear fundamentalmente em "[...] qualificar a relação dos profissionais com os usuários, sob parâmetros humanitários, de solidariedade e cidadania" (MITRE; ANDRADE; COTTA, 2012, p. 2075).

A prioridade no usuário é uma premissa recorrente nos ideais bibliotecários. Mas, infelizmente, a realidade do exercício profissional esbarra em outras instâncias da atividade bibliotecária que relegam o usuário à condição de segundo plano. São fatores diversos da rotina bibliotecária que influenciam, consciente ou inconscientemente, o estabelecimento de atitudes determinantes para o afastamento do usuário às prioridades institucionais da biblioteca. Isto posto, entende-se que "O acolhimento, enquanto diretriz operacional, propõe inverter a lógica da organização e do funcionamento do serviço [...] e que este seja organizado de forma usuário-centrado" (GOMES; PINHEIRO, 2005, p. 290-291). Assim, reforça-se que a adoção do acolhimento como princípio da cultura organizacional favorece a integração de práticas profissionais que retomam à idealização do usuário como prioridade essencial da biblioteca. Afinal, como reconhecem Santa Anna e Maia (2015, p. 273): "A trajetória evolutiva das bibliotecas, ao longo dos tempos, vem mostrando que essas unidades de informação não constituem organismos estáticos, mas sim, dinâmicos, sobrevivendo em meio às complexas mudanças, com vistas a refletir as necessidades almejadas por diferentes e exigentes públicos".

E é pela aposta nesta capacidade flexível às transformações condizentes a atender realidades sociais que se espera a ratificação do acolhimento como princípio fundamental nas relações da mediação da informação, portanto como valor instituído na própria biblioteca. Mas, caso não haja espontânea convergência para a inclusão do acolhimento como componente das atividades profissionais do bibliotecário, que seja, então, ocasionada por pressões impostas pelos próprios usuários. Afinal, a interatividade de resultados promissores somente se alcança efetivamente quando há integração pelo reconhecimento entre as diferenças dos atores envolvidos no contexto da biblioteca, especialmente entre bibliotecários e usuários. Pois, conforme entendimento de Scholze, Duarte Junior e Silva (2009, p. 306), "A convivência nos grupos humanos se dá por interações recorrentes [e] pode acontecer nas diferentes formas possíveis de viver juntos, mais próximas ou mais casuais, desde que baseadas na aceitação mútua". Deste modo, as ações de acolhimento se estruturam pela capacidade interativa da reciprocidade em que o respeito e, até mesmo, a tolerância assumem valores fundamentais das relações sociais.

Por fim, enfatiza-se que o acolhimento é uma forma representativa de se estabelecer vínculos a partir das relações interativas dispensadas para o atendimento das necessidades informacionais expressas pela comunidade usuária. Não há dúvidas de que o protagonismo social é uma capacidade profissional do bibliotecário que alicerça as bases de compromissos a fim de se interagir de modo contundente com as diversidades humanas de seu meio coletivo.

\section{Considerações Finais}

A mediação da informação se mostra como um processo integrador das múltiplas funções desempenhadas pela biblioteca. Trata-se de um marco referencial na teorização de princípios fundamentais que elucidam a competência do bibliotecário frente aos inúmeros desafios profissionais para se lidar com as operações de acesso à informação. No entanto, o usuário deve ser centralizado nas prioridades estabelecidas pela oferta de produtos e serviços na biblioteca, inclusive nas formas implícitas e explícitas da mediação da informação.

Considerar o acolhimento como princípio fundamental na estruturação de políticas de mediação da informação é proporcionar condições formais da interseccionalidade que compreendem o usuário a partir do seu lugar social. Segundo Crenshaw (2002, p. 177), a definição conceitual de interseccionalidade "[...] trata especificamente da forma pela qual o racismo, o patriarcalismo, a opressão de classe e outros sistemas discriminatórios criam desigualdades básicas que estruturam as posições relativas de mulheres, raças, etnias, classes e outras".

Com isso, é possível ampliar a lente analítica da atuação bibliotecária sobre a interação estrutural do usuário priorizando a identidade subjetiva deste sujeito e reconhecendo as nuances históricas e culturais envolvidas. Notadamente, a biblioteca 
aqui entendida representa um espaço que implica na caracterização de modelos para se desenvolver as formas de acolhimentos.

Tais arquétipos estruturais podem ser oferecidos como padrões das relações institucionais com os sujeitos individualmente percebido por uma biblioteca determinada visando atender situações implícitas e explícitas pela mediação informacional de seus produtos e serviços. Afinal, para acolher, a biblioteca precisa reconhecer e refletir os marcadores sociais das diferenças que são característicos do usuário enquanto sujeito efetivo da sua própria existência. É importante destacar que os marcadores sociais se apresentam como representações de "[...] múltiplos significados em uma combinatória de termos que apontam para novas formas de construção de alteridades" (SCHWARCZ, 2012, p. 50).

É óbvio que as dificuldades são reconhecidamente inerentes no processo de mediação da informação, quando essa atitude enfatiza o acolhimento como princípio da diretriz fundamental nas ações interativas da biblioteca. Os desafios profissionais são inúmeros que vão desde a capacitação e o envolvimento dos bibliotecários e demais intermediadores do ambiente informacional. No entanto, é exatamente pelo desafio de fazer a diferença, priorizando o usuário, que a mediação da informação assume a excelência da sua importância fundamental.

Afinal, dentre as inúmeras responsabilidades que pesam sobre a biblioteca consta a recepção mediada ao usuário de recursos informacionais. Deste modo, "Para que os usuários sejam bem atendidos é necessário, logo de início, oferecer serviços de informação, mas também oferecer serviços de acolhimento transformando a unidade em um espaço aconchegante, receptivo e familiar" (SANTA ANNA; MAIA, 2015, p. 275). Notadamente, percebe-se a importância do acolhimento para ser assimilado como característica essencial da mediação da informação. Assim, o ato de acolher deveria configurar um aspecto de importância fundamental na concepção da mediação da informação favorecendo um princípio elementar desse processo. É com este anseio que o presente artigo foi motivado e desenvolvido.

Portanto, se reconhece que o acolhimento evidencia mais que uma atitude profissional ou institucional e representa o exercício da dimensão humana para envolver práticas estabelecidas em diretrizes políticas na orientação de bibliotecas. Espera-se que a presente contribuição repercuta em outros trabalhos e pesquisas para ampliar o repertório teórico da mediação da informação.

\section{Referências}

ALMEIDA JÚNIOR, Oswaldo Francisco de. Mediação da informação: ampliando o conceito de disseminação. In: VALENTIM, Marta Lígia Pomim (org.). Gestão da informação e do conhecimento. São Paulo: Polis: Cultura Acadêmica, 2008. Cap. 3, p. 41-54.

ALMEIDA JÚNIOR, Oswaldo Francisco de; BORTOLIN, Sueli. Mediação da informação e da leitura. In: SILVA, Terezinha Elisabeth da Silva (org.). Interdisciplinaridade e transversalidade em Ciência da Informação. Recife: Néctar, 2008. p. 67-85.

ALMEIDA JÚNIOR, Oswaldo Francisco de. Mediação da informação: um conceito atualizado. In: BORTOLIN, Sueli; SANTOS NETO, João Arlindo dos; SILVA, Rovilson José da (org.). Mediação oral da informação e da leitura. Londrina: Abecin, 2015. Cap. 1, p. 9-32.

ARRUDA, Maria Izabel Moreira; OLIVEIRA, Hamilton Vieira. Um olhar sobre a evolução do conceito de mediação na Ciência da Informação. Revista Ibero-americana de Ciência da Informação, Brasília, v. 10, n. 1, p. 218 -232, jan./jul. 2017. Disponível em: https://periodicos.unb.br/index.php/RICl/article/view/2523. Acesso em: 10 nov. 2020.

CRENSHAW, Kimberlé. Documento para o encontro de especialistas em aspectos de discriminação racial relativos ao gênero. Estudos Feministas, Florianópolis, v. 10, n. 1, p. 171-188, jan./jun. 2002. Disponível em: http://www.scielo.br/pdf/ref/v10n1/11636. Acesso em: 10 nov. 2020.

FERRAZ, Marina Nogueira. O papel social das bibliotecas públicas no século XXI e o caso da Superintendência de Bibliotecas Públicas de Minas Gerais. Perspectivas em Ciência da Informação, Belo Horizonte, v.19, número especial, p.18-30, out./dez. 2014. Disponível em: http://portaldeperiodicos.eci.ufmg.br/index.php/pci/article/view/2280. Acesso em: 10 nov. 2020.

FRANCO, Túlio Batista; BUENO, Wanderlei Silva; MERHY, Emerson Elias. O acolhimento e os processos de trabalho em saúde: o caso de Betim, Minas Gerais, Brasil. Cadernos de Saúde Pública, Rio de Janeiro, v. 15, n. 2, p. 345-353, abr./jun. 1999. DOI: https://doi.org/10.1590/S0102-311X1999000200019. Disponível em: http://ref.scielo.org/9y5zb7. Acesso em: 10 nov. 2020.

GOMES, Henriette Ferreira. Tendências de pesquisa sobre mediação, circulação e apropriação da informação no Brasil: estudo em periódicos e anais dos Enancib (2008-2009). Pesquisa Brasileira em Ciência da Informação, Brasília, v. 3, n.1, p. 85-99, jan./dez. 2010. Disponível em: https://revistas.ancib.org/index.php/tpbci/article/view/187. Acesso em: 10 nov. 2020. 
GOMES, Henriette Ferreira. Mediação da informação e protagonismo social. In: GOMES, Henriette Ferreira; NOVO, Hildenise Ferreira (org.). Informação e protagonismo social. Salvador: EDUFBA, 2017. p. 27-43.

GOMES, Márcia Constância Pinto Aderne; PINHEIRO, Roseni. Acolhimento e vínculo: práticas de integralidade na gestão do cuidado em saúde em grandes centros urbanos. Interface: comunicação, saúde, educação, Botucatu, v. 9, n. 17, p. 287-301, mar./ago. 2005. DOI: http://dx.doi.org/10.1590/S1414-32832005000200006. Disponível em: https://www.scielo.br/scielo.php?script=sci arttext\&pid=S1414$32832005000200006 \&$ lng =en\&nrm=iso\&tlng=pt. Acesso em: 10 nov. 2020.

LOPES, Adriana Santos; VILAR, Rosana Lúcia Alves de; MELO, Ricardo Henrique Vieira de; FRANÇA, Raiane Caroline da Silva. O acolhimento na atenção básica em saúde: relações de reciprocidade entre trabalhadores e usuários. Saúde Debate, Rio de Janeiro, v. 39, n. 104, p. 114-123, jan./mar. 2015. DOI: http://dx.doi.org/10.1590/0103-110420151040563. Disponível em: https://www.scielo.br/scielo.php?script=sci arttext\&pid=S0103-11042015000100114\&lng=en\&nrm=iso\&tlng=pt. Acesso em: 10 nov. 2020.

MITRE, Sandra Minardi; ANDRADE, Eli lola Gurgel; COTTA, Rosângela Minardi Mitre. Avanços e desafios do acolhimento na operacionalização e qualificação do Sistema Único de Saúde na Atenção Primária: um resgate da produção bibliográfica do Brasil. Ciência \& Saúde Coletiva, Rio de Janeiro, v. 17, n. 8, p. 2071-2085, ago. 2012. DOI: http://dx.doi.org/10.1590/S1413-81232012000800018. Disponível em: https://www.scielo.br/scielo.php?script=sci arttext\&pid=S1413-81232012000800018\&lng=en\&nrm=iso\&tlng=pt. Acesso em: 10 nov. 2020.

SANTA ANNA, Jorge; MAIA, Maria de Lourdes Franklin. Manifestações simbólicas de punição/proibição em bibliotecas: espaços de acolhimento ou coerção? Revista ACB: Biblioteconomia em Santa Catarina, Florianópolis, v. 20, n. 2, p. 272-285, maio/ago. 2015. Disponível em: https://revista.acbsc.org.br/racb/article/view/988. Acesso em: 10 nov. 2020.

SANTAELLA, Lucia. Linguagens líquidas na era da mobilidade. 2. ed. São Paulo: Paulus, 2011.

SANTOS NETO, João Arlindo dos; ALMEIDA JÚNIOR, Oswaldo Francisco de. O caráter implícito da mediação da informação. Informação \& Sociedade: Estudos, João Pessoa, v. 27, n. 2, p. 253-263, maio/ago. 2017. Disponível em: https://periodicos.ufpb.br/index.php/ies/article/view/29249. Acesso em: 10 nov. 2020.

SCHOLZE, Alessandro da Silva; DUARTE JUNIOR, Carlos Francisco; SILVA, Yolanda Flores e. Trabalho em saúde e a implantação do acolhimento na atenção primária à saúde: afeto, empatia ou alteridade? Interface: comunicação, saúde, educação, Botucatu, v. 13, n. 31, p. 303-14, out./dez. 2009. DOI: https://doi.org/10.1590/S1414-32832009000400006. Disponível em: https://www.scielo.br/scielo.php?script=sci arttext\&pid=S1414-32832009000400006\&lng=en\&nrm=iso\&tlng=pt. Acesso em: 10 nov. 2020

SCHWARCZ, Lilia Moritz. Do preto, do branco e do amarelo: sobre o mito nacional de um Brasil (bem) mestiçado. Ciência \& Cultura, São Paulo, v. 64, n.1, p. 48-55, jan. 2012. DOI: http://dx.doi.org/10.21800/S0009-67252012000100018. Disponível em: http://cienciaecultura.bvs.br/scielo.php?script=sci arttext\&pid=S0009-67252012000100018. Acesso em: 10 nov. 2020.

SILVA, Armando Malheiro da. Mediações e mediadores em Ciência da Informação. Prisma.com, Porto, n. 9, p. 66-104, jun./dez. 2009. Disponível em: http://ojs.letras.up.pt/index.php/prismacom/article/view/2057. Acesso em: 10 nov. 2020.

SOUTO, Leonardo Fernandes. Informação seletiva, mediação e tecnologia: a evolução dos serviços de disseminação seletiva da informação. Rio de Janeiro: Interciência, 2010.

TESSER, Charles Dalcanale; POLI NETO, Paulo; CAMPOS, Gastão Wagner de Sousa. Acolhimento e (des)medicalização social: um desafio para as equipes de saúde da família. Ciência \& Saúde Coletiva, Rio de Janeiro, v. 15, supl. 3, p. 3615-3624, nov. 2010. DOI: http://dx.doi.org/10.1590/S1413-81232010000900036. Disponível em: https://www.scielo.br/scielo.php?script=sci arttext\&pid=S1413$81232010000900036 \&$ Ing=pt. Acesso em: 10 nov. 2020.

TRINDADE, Cristiano Santos. A importância do acolhimento no processo de trabalho das equipes de saúde da família. 2010. Monografia (Especialização em Atenção Básica em Saúde da Família) - Núcleo de Saúde Coletiva da Faculdade de Medicina, Universidade Federal de Minas Gerais, Belo Horizonte, 2010. Disponível em:

https://www.nescon.medicina.ufmg.br/biblioteca/imagem/2303.pdf. Acesso em: 10 nov. 2020.

VARELA, Aida. Informação e autonomia: a mediação segundo Feuerstein. São Paulo: SENAC São Paulo, 2007.

Artigo submetido em: 08/12/2019.

Aceito em: 01/05/2020. 


\section{OR UNIVERSIDADE FEDERAL DO CARIRI}

Este periódico é uma publicação do Programa de Pós-Graduação em Biblioteconomia da Universidade Federal do Cariri em formato digital e periodicidade quadrimestral. 